\title{
Nipah and Hendra viruses: recent advances in pathogenesis
}

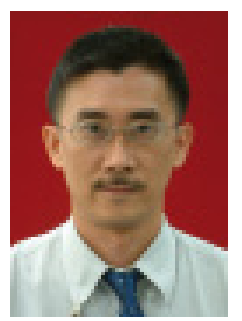

"Currently, several vaccine and treatment

modalities have already been tested and some appear to work ... A greater understanding of the viral pathogenesis of henipaviruses should lead to other significant clinical breakthroughs..."

\section{KT Wong}

Department of Pathology, Faculty of Medicine, University of Malaya, 50603 Kuala Lumpur, Malaysia mel.: +60 379492064 m Fax: +60379556845 mwongkt@um.edu.my

In 1998, an outbreak of human acute encephalitis in Malaysia led to the discovery of a novel paramyxovirus named Nipah virus (NiV) [1]. Subsequently, outbreaks were also reported in Bangladesh and India. So far, more than 500 people have been infected with a mortality of $40-70 \%[2-5]$. NiV is closely related to Hendra virus $(\mathrm{HeV})$, discovered in Australia in 1994 [6]. Hitherto, there are only seven known human $\mathrm{HeV}$ cases. Both viruses have been placed into the newly created genus Henipavirus, within the same family as the measles virus, Paramyxoviridae [7].

The natural host of henipaviruses is the pteropid or fruit bat, whose range extends through Africa, Asia-Oceania and Australia. In the NiV outbreaks in Malaysia and Singapore, the intermediate host was the pig, while in Bangladesh and India, direct bat-human and humanhuman transmissions occurred $[3,8]$. Acute NiV infection may be asymptomatic; symptomatic cases present with fever and headache or acute encephalitis that is often associated with coma. In patients who recovered from acute infection, approximately $5-8 \%$ relapsed or developed late-onset NiV encephalitis, which was thought to be clinically distinct from acute NiV encephalitis [9]. HeV infection is also associated with acute and relapsing encephalitis [10]. In general, brain imaging in acute encephalitis showed multiple discrete lesions whereas in relapsing encephalitis, the lesions were more confluent $[11,12]$.

Most of the evidence for the pathogenesis of human henipavirus infection is derived from autopsy studies of $\mathrm{NiV}$ infection [13]. In acute $\mathrm{NiV}$ infection, systemic vasculitis, discrete, plaque-like parenchymal necrosis and inflammation are found in most major organs, particularly in the CNS. Vascular endothelial damage resulted in thrombosis, vascular occlusion, ischemia and microinfarction. Viral antigens and nucleocapsids are immunolocalized to the vascular wall. Viral inclusions, nucleocapsids, antigens and RNA were also detected in extravascular parenchymal cells, especially in neurons. The pathogenesis of acute NiV infection appears to be a unique dual mechanism of vasculitis-induced thrombosis, ischemia/microinfarction and direct parenchymal cell infection. Autopsy evidence from the much rarer acute $\mathrm{HeV}$ infection suggests that the same pathogenetic mechanisms apply [10].

The pathogenesis of acute henipavirus infection in humans has been confirmed in many infection studies in animal models using the hamster, guinea pig, cat, pig, ferret and monkey [14-21]. Generally, similar to in human infections, there is systemic vasculitis and subsequent vessel wall infection, and also evidence of extravascular parenchymal cell infection.

In relapsing henipavirus encephalitis, CNSlimited lesions consisted of mildly inflamed, vacuolated necrotic lesions merging with confluent areas of more extensive parenchymal necrosis and increasing inflammation [10,13]. There were neuronal viral inclusions, antigen/ RNA and nucleocapsids but vasculitis was absent throughout. In $\mathrm{NiV}$, some lesions had a distinctive concentric or wave-like morphology [Wong KT, Unpublished Data]. These findings suggest that relapsing henipavirus encephalitis is a recurrent de novo infection rather than postinfectious encephalitis. Moreover, recurrence is unlikely to arise from extraneural foci because that would involve viremic spread to the CNS and almost certain vascular infection and vasculitis. Why does relapsing encephalitis occur? If a parallel may be drawn to subacute sclerosing panencephalitis, which is associated with mutant measles virus infection, then viral mutation is one possibility. It is possible that certain mutations may allow the virus to remain within the neurons, spread via interneuronal connections and escape the immune response. So far, no

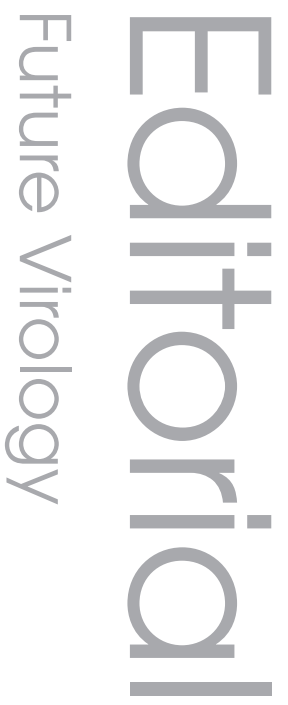

\section{future feros $_{\text {medicine }}$ fsg}


mutations have been discovered [YaIw KC, Wong KT, Unpublished Data]. The other possibility is, like measles, immunosuppression could occur with acute henipavirus infection that allows small virus foci to remain viable [22]. Over time, the virus may spread slowly to cause relapsing encephalitis. Whether or not these recurrences involve further immunosuppression by the virus or other unknown factors remain to be investigated. The time interval from subsidence of acute infection to the first symptoms of relapsing encephalitis may vary from weeks to years $[9,23]$. It is possible that acute encephalitis may continue as relapsing encephalitis without a significant interval, as was suggested by some acute $\mathrm{NiV}$ cases from Bangladesh, in which brain magnetic resonance scans demonstrated confluent lesions more typical of relapsing encephalitis than the discrete lesions of classical acute $\mathrm{NiV}$ encephalitis [24]. Immune modulation and its possible role in various manifestations of henipavirus infection and their progression therefrom need to be investigated. Whether or not a person's particular genotype could impact susceptibility to infection is unknown. There is currently no animal model for relapsing henipavirus encephalitis.

That henipaviruses share common pathogenetic mechanisms, in humans at least, is not surprising since both viruses were reported to use the same ephrin B2 and B3 ligands as virus receptors $[25,26]$. However, it is still possible that there are significant differences in the pathogenesis of $\mathrm{NiV}$ and $\mathrm{HeV}$. This should be further investigated in animal models as the number of human $\mathrm{HeV}$ cases are still relatively small. It is uncertain if there is a role for direct transnasal viral transmission to the human CNS, as was shown in pigs [16]. Last, but not least, henipaviruses with different genotypes within the same species may yet have differences in pathogenesis, therefore animal studies with NiV from Bangladesh, which has significant nucleotide differences from the Malaysian isolate, could prove interesting, particularly if combined with studies using infectious clones [27].

Currently, several vaccine and treatment modalities have already been tested and some appear to work, at least in animal models [19,20,28]. A greater understanding of the viral pathogenesis of henipaviruses should lead to other significant clinical breakthroughs in the future.

\section{Financial \& competing interests disclosure \\ The author has no relevant affiliations or financial involvement with any organization or entity with a financial interest in or financial conflict with the sub- ject matter or materials discussed in the manuscript. This includes employment, consultancies, honoraria, stock ownership or options, expert testimony, grants or patents received or pending, or royalties. \\ No writing assistance was utilized in the production of this manuscript.}

\section{Bibliography}

1. Chua KB, Goh KJ, Wong KT et al.: Fatal encephalitis due to Nipah virus among pig-farmers in Malaysia. Lancet 354, 1257-1259 (1999).

2. Goh KJ, Tan CT, Chew NK et al.: Clinical features of Nipah virus encephalitis among pig farmers in Malaysia. N. Engl. J. Med. 342, 1229-1235 (2000).

3. Harit AK, Ichhpujani RL, Gupta S et al:: Nipah/Hendra virus outbreak in Siliguri, West Bengal, India in 2001. Indian J. Med. Res. 123, 553-560 (2006).

4. Hossain MJ, Gurley ES, Montgomery JM et al.: Clinical presentation of nipah virus infection in Bangladesh. Clin. Infect. Dis. 46, 977-984 (2008).

5. Wong KT, Shieh WJ, Zaki SR, Tan CT: Nipah virus infection, an emerging paramyxoviral zoonosis. Springer Semin. Immunopathol. 24, 215-228 (2002).

6. Murray K, Selleck P, Hooper P et al.: A morbillivirus that caused fatal disease in horses and humans. Science 268, 94-97 (1995).
7. Wang L, Harcourt BH, Yu M et al.: Molecular biology of Hendra and Nipah viruses. Microbes Infect. 3, 279-287 (2001).

8. Luby SP, Rahman M, Hossain MJ et al.: Foodborne transmission of Nipah virus, Bangladesh. Emerg. Infect. Dis. 12, 1888-1894 (2006).

9. Tan CT, Goh KJ, Wong KT et al.: Relapsed and late-onset Nipah encephalitis. Ann. Neurol. 51, 703-708 (2002).

10. Wong KT, Robertson T, Ong BB et al: : Human Hendra virus infection causes acute and relapsing encephalitis. Neuropathol. Appl. Neurobiol. 35, 296-305 (2009).

11. Sarji SA, Abdullah BJ, Goh KJ, Tan CT, Wong KT: MR imaging features of Nipah encephalitis. Am. J. Roentgenol. 175, 437-442 (2000).

12. O'Sullivan JD, Allworth AM, Paterson DL et al.: Fatal encephalitis due to novel paramyxovirus transmitted from horses. Lancet 349, 93-95 (1997).
13. Wong KT, Shieh WJ, Kumar S et al:: Nipah virus infection: pathology and pathogenesis of an emerging paramyxoviral zoonosis. Am. J. Pathol. 161, 2153-2167 (2002).

14. Williamson MM, Hooper PT, Selleck PW, Westbury HA, Slocombe RF: A guinea-pig model of Hendra virus encephalitis. J. Comp. Path. 124, 273-279 (2001).

15. Wong KT, Grosjean I, Brisson C et al: : A golden hamster model for human acute Nipah virus infection. Am. J. Pathol. 163, 2127-2137 (2003).

16. Weingartl H, Czub S, Copps J et al: Invasion of the central nervous system in a porcine host by Nipah virus. J. Virol. 79, 7528-7534 (2005).

17. Marrianneau P, Guillaume V, Wong KT et al.: Primate model for the emergent Nipah virus infection. Emerging Infect. Dis. (2010) (In Press).

18. Torres-Velez FJ, Shieh WJ, Rollin PE et al.: Histopathologic and immunohistochemical characterization of Nipah virus infection in the guinea pig. Vet. Pathol. 45, 576-585 (2008). 
19. Bossart KN, Zhu Z, Middleton D et al.: A neutralizing human monoclonal antibody protects against lethal disease in a few ferret model of acute Nipah virus infection. PLOS Pathog. 5, e1000642 (2009).

20. Guillaume V, Wong KT, Looi RY et al.: Acute Hendra virus infection: analysis of the pathogenesis and passive antibody protection in the hamster model. Virology 387, 459-465 (2009).

21. Mungall BA, Middleton D, Crameri G et al: : Feline model of acute Nipah virus infection and protection with a soluble glycoprotein-based subunit vaccine. J. Virol. 80, 12293-12302 (2006).

22. Berhane Y, Weingartl HM, Lopez J et al.: Bacterial infections in pigs experimentally infected with Nipah virus. Transbound. Emerg. Dis. 55, 165-174 (2008).
23. Chong HT, Tan CT: Relapsed and late-onset Nipah encephalitis, a report of three cases. Neurol. J. Southeast Asia 8, 109-112 (2003).

24. Quddus R, Alam S, Majumdar MA et al.: A report of 4 patients with Nipah encephalitis from Rajbari district, Bangladesh in the January 2004 outbreak. Neurology Asia 9, 33-37 (2004).

25. Bonaparte MI, Dimitrov AS, Bossart KN et al.: Ephrin-B2 is a functional receptor for Hendra virus and Nipah virus. Proc. Natl Acad. Sci. USA 102, 10652-10657 (2005).

26. Negrete OA, Levroney EL, Aguilar HC et al.: Ephrin B2 is the entry receptor for Nipah virus, an emergent deadly paramyxovirus. Nature 436, 401-405 (2005).

27. Yoneda M, Guillaume V, Ikeda F et al.: Establishment of a Nipah virus rescue system. Proc. Natl Acad. Sci. 103, 16508-16513 (2006).
28. Guillaume V, Contamin H, Loth P et al.: Antibody prophylaxis and therapy against Nipah virus infection in hamsters. J. Virol. 80, 1972-1978 (2006).

\section{Affiliation}

- KT Wong

Department of Pathology, Faculty of Medicine, University of Malaya, 50603 Kuala Lumpur, Malaysia Tel.: +60 379492064

Fax: +60379556845

wongkt@um.edu.my 